\title{
The place of literature adaptation in Afghan cinema
}

\author{
Abbas mohammadi \\ Amiri Publications, Afghanistan
}

\begin{abstract}
Literature entered this art from the beginning of the invention of cinema. When we study the history of cinema, we come across a large number of films adapted from literature. This shows that literature and cinema are mixed. Cinema and literature are two inseparable pairs because cinema has needed and will need literature and drama in all periods of its development. In principle, it can be said that cinema has no meaning without literature. In all countries there are native stories and original stories that screenwriters use to write their screenplays. Adaptation is a way to produce films from short and long stories, legends, novels, plays and ancient works of the countries of the world. When one looks at movies adapted from stories and novels, we see that most of the adaptations have been dramatically successful. At least in terms of storytelling, they have been able to satisfy their audience. But in Central Asian countries, especially in Afghanistan, adaptation has been very poor. Afghan screenwriters are more committed to original screenplays and have made less effort to adapt to literature. Cinema can never be separated from literature because half of the cinema that is drama is taken from literature. It should not be forgotten that every film that is made is an adaptation of the natural world and the world around us. Literature is essentially a drama about what is happening around us. Cinema can make it a tangible image. But when filmmakers want to adapt from literature, they focus on the events of the story instead of getting more meaning, which leads to the failure of cinema to adapt to literature. This is the situation in Afghan cinema, which has led to the failure of adaptation in Afghan cinema.
\end{abstract}

Keywords: Cinema, Literature, Afghanistan, Drama, Screenplay.

\section{Introduction}

An adaptation is essentially a re-creation of a story or a novel created by an author. An adaptation is an inspiration from another created work, which can be a movie, a book, a painting, a poem, or anything else. The adapter makes a new creation. He modifies that original work in a different way so that only traces of that original work can be seen in his new work. In many adaptations, when we look closely, we see that more than fifty percent of the original work has changed. In such a case, it is difficult to distinguish the original work from this new work. But in some types of adaptations, it is tried to preserve the evolution of the story, the characters and, as far as possible, the characteristics of the original work. The basis of recreation is imagination, and the newly created work will be an independent, fresh and original work.

In cinematic adaptation, different aspects of the work can be considered and the adaptation should not be limited only to the interpretation of the subject from the literary work. Sometimes it is possible that the result of the adapter's work is in the appearance of the work. In cinema as a multifaceted art that is a combination of several other arts it can be viewed from the perspective of: literature (idea, subject, writing style, tone and expression in the screenplay section), from the perspective of: graphics, image, color and light (lighting and filming), From the point of view: theatrical (actors' acting methods), from the point of view: painting and architecture (methods of combining colors in costume and stage design) and from the point of view: music (application and use of music and sound in the film) had various adaptations. This means that perhaps in an adapted film, only one of these literary works, or another cinematic film, is used and in another film other methods are used.

One of the most important principles of cinematic adaptation is the issue of taking known subjects from foreign literary and artistic works and adapting them to the culture and customs and social principles of this border and environment such as clothing, language and traditional customs. It is not so easy to coordinate. Given the rich resources available in the cultures and traditions of different countries, especially in ancient literature, in the current situation, not much significant work has been done in the cinema of the countries, especially in Asian countries, and the cinema and television organizations do not pay much attention to this issue.

\section{Adaptation}

Cinema is not as old as other arts in the world. If the life of other arts goes back to ancient times, but the life of cinema is a little over a hundred years. But this young visual art in a short time has been able to surpass other arts and make the most of its ability to penetrate its audience but it should not be forgotten that cinema also uses other sciences and arts to convey its message to the audience, one of which is literature. Since the advent of cinema, adaptation of literature has had a special place in the art of cinema. One of the reasons for this position is that books have been read by people before they became films, so the mind of the audience is familiar with the story and narration of that book. For this reason, the popularity of that story is known, and as a result, the success of the film is predetermined. Therefore, a film made based on a story and literary books will always be a relative guarantee for the filmmakers. This issue has increased significantly in recent decades, when economic issues in cinema have become more and more important and 
have become one of the most important parts of the film industry. As we can see, many successful and best-selling films in world cinema are adapted from some of the best-selling books of the year in recent decades. Prominent examples are Harry Potter, Lord of the Rings, etc.).

The important debate is how to make a cinematic adaptation of literature. This question may not be easily answered. Because many aspects have to be considered. Generally, what connects cinema and literature is what the connecting point between all the existing arts is. In fact, that common point between the arts is nothing but narrative. In all arts, there is a kind of narrative. In every work of art, such as: painting, literature, music, sculpture, cinema, etc., we see the story and character and the specific angle of view of the same art. So all the arts have a story to tell to their audience. But the type and mode of narration in each of these arts is unique to the art itself. Therefore, there is a big difference between the type of narrative in cinema and literature.

Too often, literary critics object to literary adaptations of cinema. There is a feeling in reading a book that does not arise when watching a movie, but it should not be forgotten that the story is written based on the mind of the author. And when a filmmaker makes a film out of it, he has his own mentality, so one cannot expect the minds of these two people to be one. Because each of them has its own kind of view and its own narrative of the story. And each try Create the story the way they like. When a story turns from a writer's mind into a book, the reader turns the narrative of the story into a mental image that he is interested in with his mind in his thoughts. But when a filmmaker makes a film from a story, he turns that story into an image based on his mind and shows the audience that the audience of the film cannot see anything outside of what the filmmaker is showing him. That is why sometimes the audience is not satisfied with the adaptation films.

In many cases, the space that the author has formed in the story is not formed in the film, because no matter how prominent and strong it is in terms of storytelling and characterization, Again, it is a verbal and written work whose value is in the form of expression and writing of the story. If cinema is a visual and audio art. In literature, words and sentences are used to shape the story and its narration. But in cinema, instead of words, shots and shots are used. Thus, the feeling that the book conveys to the reader by describing and explaining the book with several lines or several paragraphs, the cinema conveys the same to the viewer in several open or closed views. It is quite clear that the feeling conveyed to the audience in these two ways is completely different. It should not be forgotten that a subject such as the description of a scene or the design of a scene, which may reach several paragraphs or pages in the book, can be shown to the audience by the cinema using one or two short scenes. Another very important difference between literature and cinema is that the book leaves parts of the story to the reader's imagination. If in cinema the elements you see in the scene are fixed. In fact, the person who reads the book, through the mentality that is created in his mind by reading the words, reaches the image that he has made of the words and sentences. While the cinema spectator reaches a special mentality about that subject through objective and visual effects. It should not be forgotten that in cinema, the spectator is completely free to judge the characters and their pathology. But this freedom of decision is much greater in the literature, and it covers many issues of the scene and the characters.

Adapted films can never be ignored because many of the films that have been able to laugh well and win many awards at major festivals around the world have their screenplays adapted from novels. A large number of films are made each year, and an adaptation film is generally nominated for an Academy Award each year, which shows that adaptation films have a place everywhere.

Linda Seeger makes this clear in her book writing an Adapted Screenplay. She believes that most of the Oscar-winning films are adaptations. Seeger says nearly half of all TV movies are adapted, not just in cinema but also on television. "When we look at the statistics that Linda Seeger gives from adaptations, there is a bit of interaction," says Linda Seeger. Most Oscar-winning or Emmy-winning films are adaptations. Consider the following amazing statistics:

\section{$85 \%$ of all Academy Award-winning films are adaptations.}

$45 \%$ of all TV movies are adapted. Nevertheless, $70 \%$ of all Emmy Award-winning films have been selected from these films.

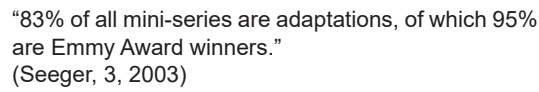

Linda Seeger mentions some of the most popular adaptations in her two years in her book. And he says: "Most of the films of the year are adaptations. In December 1989, adaptations such as "Sea of Love", "Rose Family War", "Devil-Woman", "Little Mermaid", "Henry V", "My Left Foot", "Bear", "Glory", "Black Rain", and "Inanimate Magnolia" can be named. In 1990 the films "Awareness", "Postcards from the Border", "Flame of Arrogance", Memphis Bell "," Dancing with Wolves "," Russian House "," John and Henry "," Luck "," Good Comrades “ "” Hamlet "," Cyrano Doberjac "," Pocket Bears "and" Misery "were adaptations." (Seeger, 4, 2001).

This statistic from the productions of the adaptation films presented by Linda Seeger is amazing and is $100 \%$ surprising for cinematographers and screenwriters. In many festivals, adaptation films are given more importance than original films. Given such a high number, we should think more about producing films from stories and novels. In principle, more attention should be paid to adaptation. Efforts should be made to focus more on teaching adaptation and how to write screenplays adapted from existing novels and stories. Before we can adapt, we need to know 
how we want to do it. So in the first step we need to know the types of adaptations.

\section{Types of adaptations}

In the world of art, literature and adaptation, there are three types of adaptation that are mostly used in cinema, and each of these types of adaptations has its own characteristics.

1. Free adaptation.

2. Loyal adaptation.

3. Word-for-word adaptation.

Here is a brief description of these adaptations to get more familiar with them.

\section{Free adaptation}

In free adaptation, they usually take an idea or a situation or a character from a literary source and try to develop it independently and create a new character from it.

\section{Loyal adaptation}

In the faithful adaptation, an attempt is made to preserve the originality of the literary work as much as possible, the screenwriter tries to recreate the written literary work in the form of cinema. This type of adaptation tries to preserve the events and many characters of the literary story and tries not to destroy them.

\section{Word-for-word adaptation}

This type of adaptation usually occurs when the script is based on a play. It should not be forgotten that the adaptation does not end with just these cases, but in the cinematic adaptation we can pay attention to other aspects as well. That is, we should not limit the adaptation only to the content of the work. Because adaptation in cinema can be done not only from literature but also from other works of cinema, television, theater, painting and even music.

\section{How to adapt?}

When you want to adapt a novel or a story, you have to go through several stages. Linda Seeger explains these steps well Linda Seeger says that to write an adapted screenplay, you have to follow a few steps very well and accurately. To make a strong adaptation from real life. "It's easy to adapt some real-life adventures," says Seeger If you follow the following paragraphs, you will find out whether there is a logical possibility for successful creation of certain materials or not?

1. An important event that focuses on your topic. Even real epic stories like Gandhi's focus on his particular work to bring about nonviolent change in India.

2. Adventures that go to the peak. The famous story of the murders of construction workers has two possible peaks, depending on where you start with the murder.

3. Empathetic main characters. Do you like the characters? Are they separated? Do we want to spend time with them? Most real-life adventures focus on the fascinating characters who have helped the world.

4. Adventures that cover a short period of time. The shorter the time period, the easier it is to keep the story focused.

5. Continuous ethnic relationship of at least two personalities. Drama is about relationships. People are very rarely alone if your screenplay character has lived most of his life alone, you will have a hard time creating a dynamic and dramatic story.

6. A story that can be defined visually. Climbing Mount Everest is visual. Whoever wants to tell the story of the Americans is not doing anything visual, it is arresting the drug dealers visually.

7. The dramatic line of the climax instead of the adventure that takes place. Stories that are stacked step by step to get to an important point are easier to turn into a movie than adventures that take place. (Ceegar, 73, 74, 75, 2001).

So if we want to produce an adaptation, we have to follow the steps mentioned by Linda Seeger in the first place. We can then adapt a literary or artistic work for a feature film and write a screenplay. Of course, we should not forget that we do all these things so that the filmmaker can create a cinematic image from that literary text. "Therefore, the formation of a fixed or moving image must first be in order to present a specific purpose, opinion and vision by the filmmaker to the viewer. "Secondly, the choice of the subject and the way it is presented should be in a way that can guide the senses and the association of our meaning to the correct understanding of the subject, and not cause deviation and misunderstanding." (Baser, 13, 14, 2010).

Too often, some novice screenwriters think that stories adapted from people's lives should come to life in the same way as they do in normal life. But we should not forget that the film is not a normal life, but has a special world of its own. Wexler separates the hero from ordinary life. "The hero faces a problem or a challenge or an adventure that he has to go through. "Once the story is invited, the hero can no longer live in peace in the ordinary world." (Wiggler, 2011, 21).

\section{Adapted in Afghanistan}

Afghanistan, like other countries in the world, has paid special attention to this emerging art since the birth of cinema. Amanullah Khan, the king of Afghanistan at the time, brought a camera and video camera to Afghanistan on a trip to Europe. That young people and those interested in this art in Afghanistan are attracted to it. That young people and those interested in this art in Afghanistan are attracted to it. The arrival of the video camera in the country caused Afghan filmmakers to try to produce films based on the normal 
life of the Afghan people. Many films were made based on the lives of the people in this country. On the other hand, storytellers have long been based on the life of the Afghan people. But the problem was that Afghan storytellers and filmmakers could never work together. Therefore, in the past, not many films based on stories have been made in this country, because in the early days of cinema in Afghanistan, cinema was controlled by the government and only government programs and reports were broadcast to the people and later they turned more to Western and Indian films. This can be considered a defect in Afghan cinema.

Despite all these conditions, many films were produced in Afghanistan and were exposed to the audience. But nothing has ever been written about these films, and to this day, unfortunately, there is no book about Afghan cinema. It can be said that this is a very big violation of the literature and cinema. That's why writing about Afghan cinema is a bit difficult. To get information about Afghan cinema, a lot of research is needed to find a few things.

In pre-revolutionary Afghan cinema, some films were made, such as Saeed Orekzay's "Men Promise". The film is an adaptation of a story of the same name by Akram Osman, an Afghan writer, and reflects the culture, social relations and traditions of the people of ancient Kabul. The film was very well received by the people. At the same time, films made with original scripts failed to achieve the status of "Men Promise." This indicates that, like the rest of the world, Afghanistan is a film based on literature. They have a special place among the audience. During this period, many films were produced in Afghanistan, some of which can be said to have been well received by the audience. And some failed commercially.

Afghan cinema did not produce much in Afghanistan before the war. During the war, film production almost stopped. But the heyday of filmmaking in Afghanistan dates back to the 1960s, when communist rule was in power in Afghanistan. A time when Afghan cinema was booming. But there are no adaptations among these films.

Cinema was revived after the Taliban rule in Afghanistan, when film production in the country was completely stopped. Afghan filmmakers tried to produce the film, but the number of such films was not very high. But the film had an original script. The film, made after a difficult time in Afghanistan, was a strong point for Afghan cinema. Not many films had been made before this time, and those that were made had mostly original screenplays.

Perhaps one of the reasons why a screenplay for cinema was not adapted from literature in pre-war Afghanistan was the lack of stories and novels, which was essentially the lack of writers in the country. Perhaps the fact that Siddiq Barmak made the foreign film is also the reason why he chooses the script of this film from one of the stories of Houshang Moradi Kermani, one of the Iranian writers, and makes this film based on a story by this author. But after the Taliban rule and the presence of democracy in Afghanistan, adapted cinema came to life.
Perhaps the first film adaptation after the Taliban rule in Afghanistan is Atiq Rahimi's "Ash and Soil". This film is originally an adaptation of Atiq Rahimi's own novel Ash and Soil. But the script was adapted by Composia Partovi, the screenwriter of the Iranian writer, and Atiq Rahimi made the film himself. The film Ash and Soil has won more than 10 awards in various festivals around the world. Ash and Soil was screened in the New Look Award category at the 2004 Cannes Film Festival, and it was a great achievement for Afghanistan after "Osama" that an adaptation film from Afghanistan has been able to participate in one of the world's most prestigious festivals. But this film could not open a place for itself in the eyes of the general public. Perhaps one of the reasons is that the film has a philosophical theme and this is to be expected. That philosophical films cannot be popular with the general public and fail in the sales market. But that does not mean that Ash and Soil is not a good movie. Because this film has its place among special audiences who are filmmakers and cinema lovers.

Atiq Rahimi makes his films based on the novels he writes. But one of the films based on one of the most famous novels of the famous Afghan writer Khalid Husseini is "The Kite Runner". The kite novel became one of the best-selling books in the world at the time of its publication Mark Forster's film based on this novel was also a good film that was able to attract critics. The film was nominated for an Academy Award in 2007. Nominated for a festival such as the Oscars shows that the film was a good adaptation of the published novel.

Another film that was made in Afghanistan after the Taliban and gained a good position for itself is "Sang Sabur". This film is also an adaptation of the film made in Afghanistan by Afghan writer Atiq Rahimi. "Sang Sabur" is a realistic film that narrates the life of an Afghan woman. And in its sub-sections, it deals with the problems and subcultures of traditional Afghanistan. The film gently tells the story of Afghan women. Given that the film is an adaptation of the novel, but in many parts of the film we see the difference between the novel and the film. Like the beginning of a movie, which is almost different from the beginning of a story. Because the story begins with a sentence that conveys the author's neutrality to the place if this is not the case in the film, with the space it conveys to the audience from the house and the type of house design It is very clear that the place is somewhere in Afghanistan. There is no news of the author's neutrality in the film.

\section{Result}

With all these descriptions that have been said, when we look at the films made in Afghanistan, we come across a very small number of films. Adapted from novels or stories written by authors. In recent years, young Afghan writers have written and written stories. Many stories and novels have been written inside and outside Afghanistan. But filmmaking has never tried to make a film out of those stories. Many Afghan screenwriters who cannot adapt novels and stories because of their inability to adapt. But it should 
not be forgotten that in a country like Afghanistan, film production is very low and it can be said that there is no film production at all, when there is no film production, it will not be an adaptation.

\section{Resources:}

Ciger, Linda. (2001), writing an adapted screenplay, translated by Akbari, Abbas. Tehran, Niloufar.

Geller, Christopher. (2011), A Mythical Structure in Story and Screenplay, Translated by Abbas Akbari. Tehran, Niloufar.

Basir, Azar. (2010), Guide for Young Fossil Makers, Tehranamir Kabir.

\section{Filmography:}

Men Promise, directed by Saeed Orkazi, Afghanistan.

Alien. (1988). Directed by Siddiq Barmak, Afghanistan.

Osama. (2003). Directed by Siddiq Barmak, Afghanistan.

Ash and dirt. (2004). Directed by Atiq Rahimi, Afghanistan.

The kite Runner. (2007). Directed by Mark Forster, USA.

Sang Sabur. (2012). Directed by Atiq Rahimi, Afghanistan. 